\title{
Spectrometric and morphological characterization of condensed phase zirconium species produced during electrothermal heating on a graphite platform
}

\author{
M. A. Castro, ${ }^{a}$ A. J. Aller, ${ }^{* a}$ A. McCabe, ${ }^{b}$ W. E. Smith ${ }^{b}$ and D. Littlejohn ${ }^{b}$ \\ ${ }^{a}$ Department of Biochemistry, Area of Analytical Chemistry, University of León, \\ E-24071 León, Spain.E-mail: dbbjaf@unileon.es \\ ${ }^{\boldsymbol{b}}$ Department of Pure and Applied Chemistry, University of Strathclyde, 295 Cathedral Street, \\ Glasgow,G11XL.E-mail:d.littlejohn@strath.ac.uk
}

Received 3rd November 2004, Accepted 14th March 2005

First published as an Advance Article on the web 7th April 2005

Condensed phase zirconium species, produced over the temperature range $200-2500{ }^{\circ} \mathrm{C}$, were analysed using scanning electron microscopy (SEM), energy dispersive (ED) X-ray spectrometry, attenuated total reflectance (ATR) Fourier transform infrared (FT-IR) spectrometry and Raman spectrometry. Very similar results were derived using pyrolytic and non-pyrolytic graphite platforms. Zirconia or zirconia mixed together with alumina in a solid solution were the predominant species on the platform surface up to about $1500{ }^{\circ} \mathrm{C}$. The presence of alumina prevents conversion of the tetragonal phase of zirconia to the monoclinic phase, which is dominant for zirconia alone. Above $1500{ }^{\circ} \mathrm{C}$, aluminium and zirconium follow independent thermochemical transformations; reduction of zirconia and alumina by graphite occurs, but aluminium species are volatilised, whereas some $\mathrm{Zr}$ metal remains on the surface after a full heating cycle at $2500{ }^{\circ} \mathrm{C}$, provided that $100 \mu \mathrm{g}$ of $\mathrm{Zr}$ is initially deposited on the platform. There was no evidence that zirconium carbide is formed to any significant extent and so chemical modification by $\mathrm{Zr}$ in ETAAS seems to involve the effects of zirconia or $\mathrm{Zr}$ metal on the analyte.

\section{Introduction}

Metal-based chemical modifiers have been used widely in electrothermal atomic absorption spectrometry (ETAAS) to combat matrix interference effects. Nickel in the nitrate form, ${ }^{1}$ palladium or a mixture of palladium and other metals (magnesium, copper, cobalt, nickel) ${ }^{2-4}$ can improve the determination of many volatile analytes by permitting the use of higher than normal pyrolysis and atomization temperatures. Recently, other Pt group metals ${ }^{5}$ and metals that form highmelting carbides or oxides, such as zirconium, have found favour as permanent modifiers that produce a longer lasting coating on the graphite tube or platform..$^{6-12}$ It has been shown, through various studies, that the permanent modification approach suffers from certain drawbacks as well as providing some successes ${ }^{13-18}$ in ETAAS, with different and even contradictory mechanisms of the analyte modification process proposed.

As most samples analysed by ETAAS contain matrix salts, it is equally important to consider the influence of a modifier on the concomitant species that may act as interferents. For example, the interference effects of aluminium salts have been studied extensively, ${ }^{19-23}$ but, in many cases, the modifierinterferent interactions remain unclear.

In this work, the identification of condensed phase zirconium species formed on non-pyrolytic and pyrolytic graphite platforms during the heating of zirconium (as zirconyl chloride), or zirconium (zirconyl chloride) mixed together with aluminium (as nitrate), was carried out over the temperature range $200-2500{ }^{\circ} \mathrm{C}$. The salt residues formed after heating the samples to different temperatures were analysed by scanning electron microscopy (SEM), energy dispersive (ED) X-ray spectrometry, attenuated total reflectance (ATR) Fourier transform infrared (FT-IR) spectrometry and Raman spectrometry. Although these techniques do not have the required sensitivity to study analyte-modifier chemistry at typical ana- lyte concentrations, they are appropriate for investigation of the thermal chemistry of modifiers such as zirconium, and zirconium-interferent interactions, as they permit the morphological visualization and chemical identification of solid microresidues on the platform surface. ${ }^{23-29}$

\section{Experimental}

\section{Instruments and operating conditions}

Electrothermal atomic absorption spectrometry. A Thermo Jarrel Ash atomic-absorption spectrometer (SH 11), equipped with a graphite atomizer (Model CTF-188) and Smith-Hieftje background correction, was used. A standard uncoated rectangular graphite tube was used with either non-pyrolytic or pyrolytic graphite-coated graphite platforms. Argon (99.995\% purity) served as the purge gas and solutions $(10 \mu \mathrm{l})$ were injected manually. The temperature programme (Table 1) was always fully completed from the dry to cleaning stages. However, the temperature values for the pyrolysis, atomisation and cleaning stages were identical and raised through the temperature range $200-2500{ }^{\circ} \mathrm{C}$ up to each stated maximum value; the gas flow was switched on and off during the programme to mimic normal analysis conditions. The temperature of the platform surface was regulated using the spectrometer temperature selector, previously calibrated using an infrared thermometer (Ircon Direct-Viewing, Model A-39711-20), taking the emissivity of the platform into account. The infrared thermometer was focused onto the platform surface through the injection hole and temperature measurements (precision $\pm 10{ }^{\circ} \mathrm{C}, n=5$ ) were correlated with the spectrometer temperature selector position. Once thermal treatment of the sample at the selected temperature was complete, the platform was removed from the atomiser and placed in a desiccator until analysis. 
Table 1 Temperature program (pyrolysis 1, pyrolysis 2, atomisation and cleaning temperatures were set at the lowest value for the first experiment, and then sequentially raised at intervals for further studies up to the corresponding maximum temperature value stated on each stage)

\begin{tabular}{lllll}
\hline Parameter & Dry & Pyrolysis 1 & Pyrolysis 2 & Atomisation \\
\hline Temperature $/{ }^{\circ} \mathrm{C}$ & 150 & $200-375$ & $200-500$ & $200-2500$ \\
Ramp time $/ \mathrm{s}$ & 0 & 15 & 15 & 0 \\
Hold time $/ \mathrm{s}$ & Low & 0 & 0 & 4 \\
Argon flow & Medium & Low & 200-2500 \\
\hline
\end{tabular}

Scanning electron microscopy. Electron microprobe analysis of the graphite platform surface was performed in a JEOL scanning electron microscope (Model JSM-6100), equipped with an energy-dispersive X-ray detecting system (LINK), operated under recommended conditions $(15 \mathrm{kV}$ acceleration voltage and $5 \mathrm{nA}$ probe current).

Fourier transform infrared spectrometry. Infrared spectra in the $400-5000 \mathrm{~cm}^{-1}$ region were recorded on a PerkinElmer System 2000 Fourier transform spectrometer (Norwalk, CT, USA) equipped with an air-cooled deuterium tryglycine sulfate (DTGS) detector. The attenuated total reflection (ATR) accessory utilized was a PerkinElmer in-compartment HATR ACCY-FLAT (2000), with flat top-plate fitted with a 25reflection, $45^{\circ}, 50 \mathrm{~mm} \mathrm{ZnSe}$ crystal. Reproducible contact between the crystal and the sample was ensured by use of a variable pressure clamp assembly $(2000 / \mathrm{GX})$. Prior to each analysis, a $\mathrm{ZnSe}$ background was scanned at $2 \mathrm{~cm}^{-1}$ resolution; for each spectrum, 400 scans were co-added. In an effort to minimize problems from baseline shifts, the spectra were baseline-corrected and normalized using the maximum-minimum normalization in the OPUS software.

Raman spectrometry. Raman spectra were obtained using a Renishaw spectrometer fitted with a CCD detector and an Olympus optical microscope. Raman spectrometry measurements were performed at room temperature using the $514.5 \mathrm{~nm}$ line of an argon-ion laser as the excitation source; the power
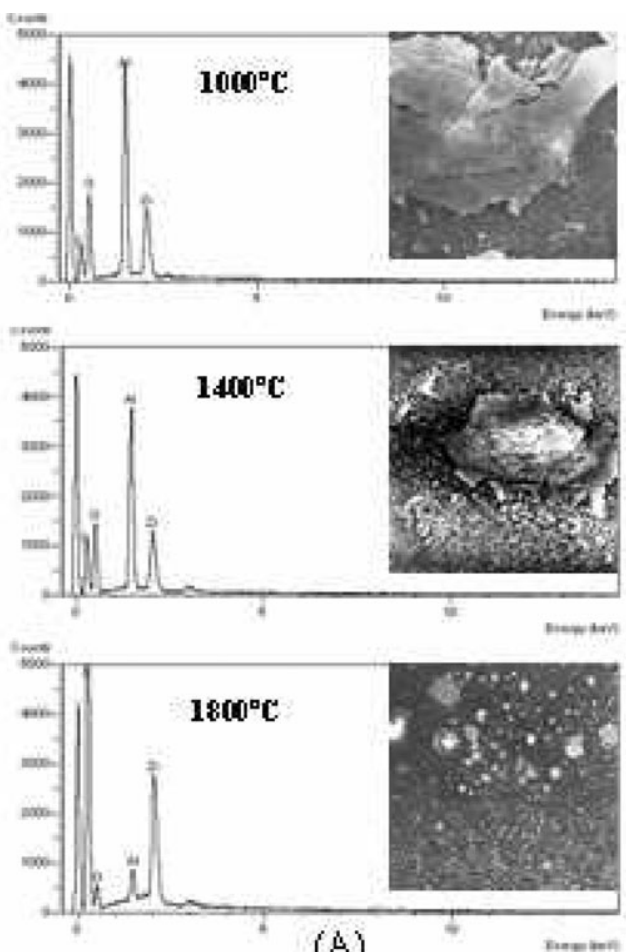

(A) level was set nominally at $100 \%$, but it had to be reduced on several occasions due to saturation of the detector. The experimental conditions were $10 \mathrm{~s}$ accumulation time, 1 min acquisition time, and a $\times 20$ objective; spectra were scanned from 200 to $4000 \mathrm{~cm}^{-1}$ and the results were processed using GRAMS20 software.

A pH-meter (Crison Model Digit 505) was used to measure the acidity of the aqueous phase, when necessary. A Mettler AE 240 semi-micro analytical balance (sensitivity $\pm 0.01 \mathrm{mg}$ ) was used to weigh chemicals.

\section{Chemicals}

Zirconium, aluminium and arsenic stock solutions (10000 $\mu \mathrm{g}$ metal $\mathrm{ml}^{-1}$ ) were prepared by dissolving amounts of zirconyl chloride, aluminium nitrate and arsenic(III) oxide $\left(\mathrm{As}_{2} \mathrm{O}_{3}\right)$, respectively, in a volume of distilled, de-ionized water (resistivity $18 \mathrm{M} \Omega \mathrm{cm}$ ). Working solutions were prepared by dilution of the stock solutions immediately prior to their use. All chemicals used in this study were of analytical reagent grade and were obtained from Merck.

\section{Results and discussion}

\section{SEM and ED X-ray spectra}

Fig. 1 shows general SEM pictures of the dry residue formed on non-pyrolytic and pyrolytic graphite platforms during the heating cycle of a mixture of zirconium and aluminium salts at
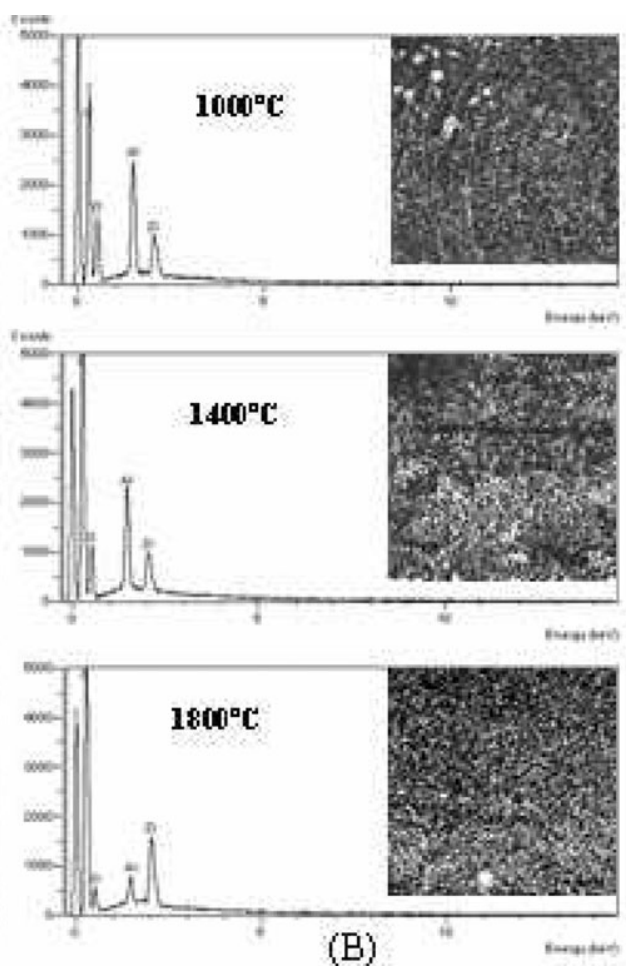

Fig. 1 Secondary electron pictures $(\times 27)$ with the corresponding ED X-ray spectra, which show general morphological and chemical changes of the solid residue of aluminium and zirconium salts $(100 \mu \mathrm{g}$ each) on a (A) non-pyrolytic and (B) pyrolytic graphite platform heated to different temperatures. 
three temperature values. General morphological and chemical transformations were noted above $1400{ }^{\circ} \mathrm{C}$ (Fig. 1). The solid residues appear to be more evenly dispersed on the pyrolytic graphite platform. The ED X-ray spectra ( $\mathrm{K}$ lines for $\mathrm{Al}$ and $\mathrm{O}$, and $\mathrm{L}$ line for $\mathrm{Zr}$ ) suggest that the main compounds on the platform surface are alumina and zirconia, up to $1400{ }^{\circ} \mathrm{C}$. The intensity of the aluminium and oxygen ED X-ray peaks decreased proportionally above $1400{ }^{\circ} \mathrm{C}$, as it was noted that the $\mathrm{Al} / \mathrm{O}$ intensity ratio remained constant with change in temperature for both types of platform (Fig. 2). Above $1400{ }^{\circ} \mathrm{C}$, the $\mathrm{X}$-ray peak of $\mathrm{Zr}$ increased in intensity relative to that of $\mathrm{Al}$, mainly for non-pyrolytic platforms. This could mean that losses of aluminium occurred at lower temperatures than for zirconium.

Up to about $1000{ }^{\circ} \mathrm{C}$, the dry residue on the non-pyrolytic graphite platform surface has two different morphological aspects with the same chemical composition; irregular particles (Fig. 3, left) on top of a lower broken layer (Fig. 3, right). The black-white element distribution mappings indicate that there is close spatial correlation between aluminium, oxygen and zirconium, which suggests that the prevalent chemical species are alumina mixed together with some zirconia. However, some spatial distributions also show zirconium to be closely correlated to aluminium at some microlocations, and with oxygen in other micro-spots. The formation of a solid solution between aluminium and zirconium may also be possible, as proposed by Damyanova et al., ${ }^{30}$ although for different experimental conditions. The formation of aluminium metal seems to occur at the edges of the particles, as the intensity of the oxygen and carbon X-ray peaks in spectra obtained for these locations are significantly smaller than that of aluminium (Fig. 4A). Bubble-like particles were detected (Fig. 4B) that have different chemical composition from that of the background mixture. A phase transition from the aluminium and zirconium hydroxide phase to the oxide phase above $\sim 300{ }^{\circ} \mathrm{C}$ may be behind the formation of the bubble-like structures. When solution contained $1 \mathrm{M}$ nitric acid, the bubble-like particles were not formed and only irregular particles with slightly greater amount of $\mathrm{Zr}$ were observed.

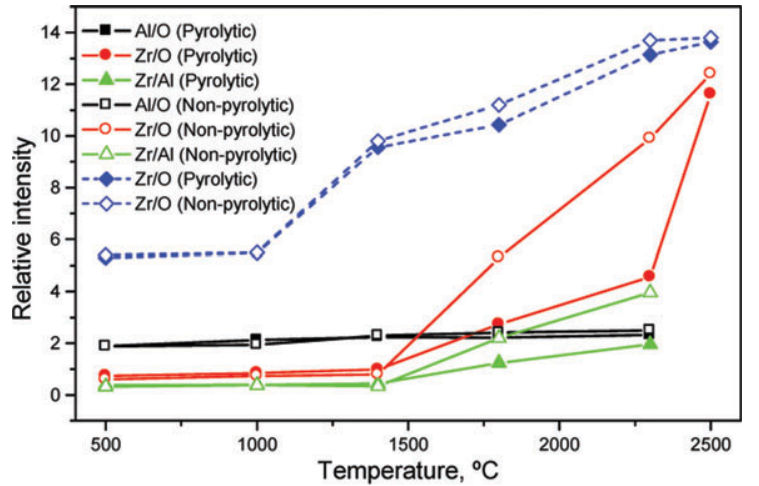

Fig. 2 Several intensity ratios derived from the ED X-ray spectra using non-pyrolytic and pyrolytic graphite platforms heated to different temperatures. Broken lines refer to the zirconium alone case.

Results obtained at $1400{ }^{\circ} \mathrm{C}$ were similar to those at $1000{ }^{\circ} \mathrm{C}$ (Fig. 5). However, the yellow point density patterns in the twoelement distribution mappings indicate that the distribution of $\mathrm{Zr}$ is not so closely correlated with that of $\mathrm{Al}$ or $\mathrm{O}$. The yellow point density represents the relative coincidence of the two selected elements represented by different colours (red and green). At $1400{ }^{\circ} \mathrm{C}$ and above, changes in the intensity of ED $\mathrm{X}$-ray peaks of $\mathrm{Al}$ and $\mathrm{O}$ depend on the physical characteristics of the solid particles and whether or not they are in contact with the surface of the graphite platform. Smaller particles apparently contain a relatively lesser amount of $\mathrm{O}$ than do larger particles.

The most noticeable morphological and chemical transformations of the solid residue on the platform surface were noted above $1500{ }^{\circ} \mathrm{C}$. At $1800{ }^{\circ} \mathrm{C}$, two different types of particles were formed: round or spherical particles (Fig. 6A) and flower-like or irregular particles (Fig. 6B). The round particles contain mainly $\mathrm{Zr}$ (Fig. 6A(b)), with minor amounts of $\mathrm{Al}$ in some cases (Fig. 6A(a)). Some parts of the round particles seem to be composed of zirconium carbide, as indicated by the good spatial coincidence between the $\mathrm{Zr}$ and $\mathrm{C}$ in the distributions
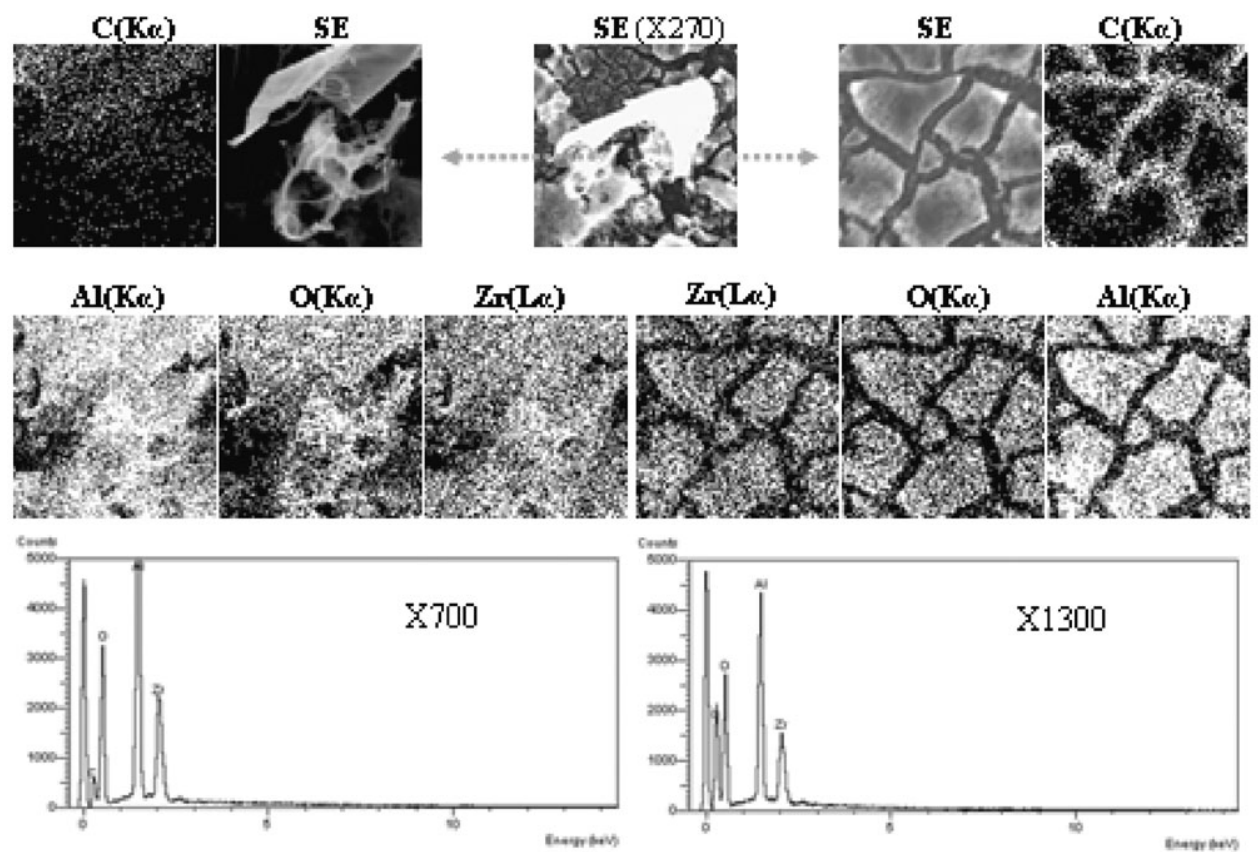

Fig. 3 Secondary electron (SE) picture $(\times 270)$ (top centre) showing a particle and the solid lower layer produced on a non-pyrolytic graphite platform containing $100 \mu \mathrm{g}$ each of aluminium and zirconium salts heated to $500{ }^{\circ} \mathrm{C}$. To the left and right of the SE $(\times 270)$ picture, element distribution mappings with the corresponding ED X-ray spectra derived from the particle (left pictures) and the lower solid layer (right pictures) are included. 

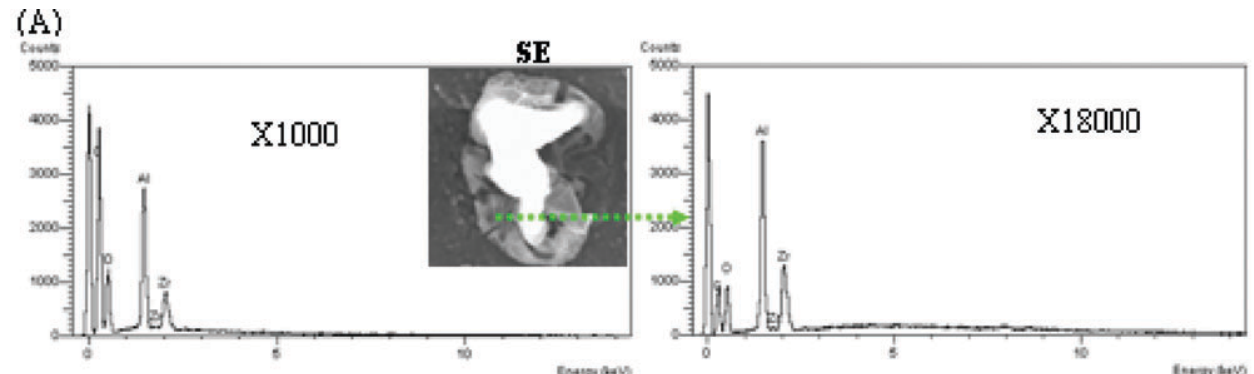

(B)
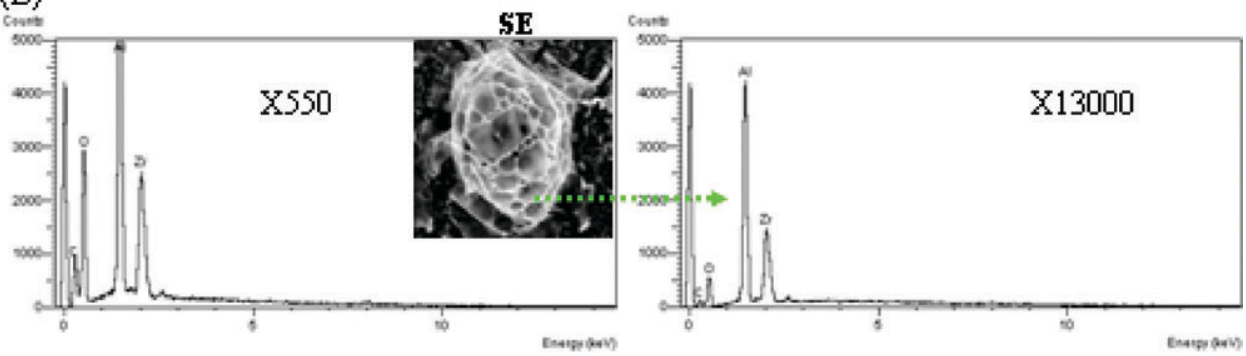

Fig. 4 ED X-ray spectra and secondary electron pictures, taken as in Fig. 3, but from two different locations on a non-pyrolytic graphite platform heated to $1000{ }^{\circ} \mathrm{C}$ showing (A) irregular and (B) bubble-like particles.
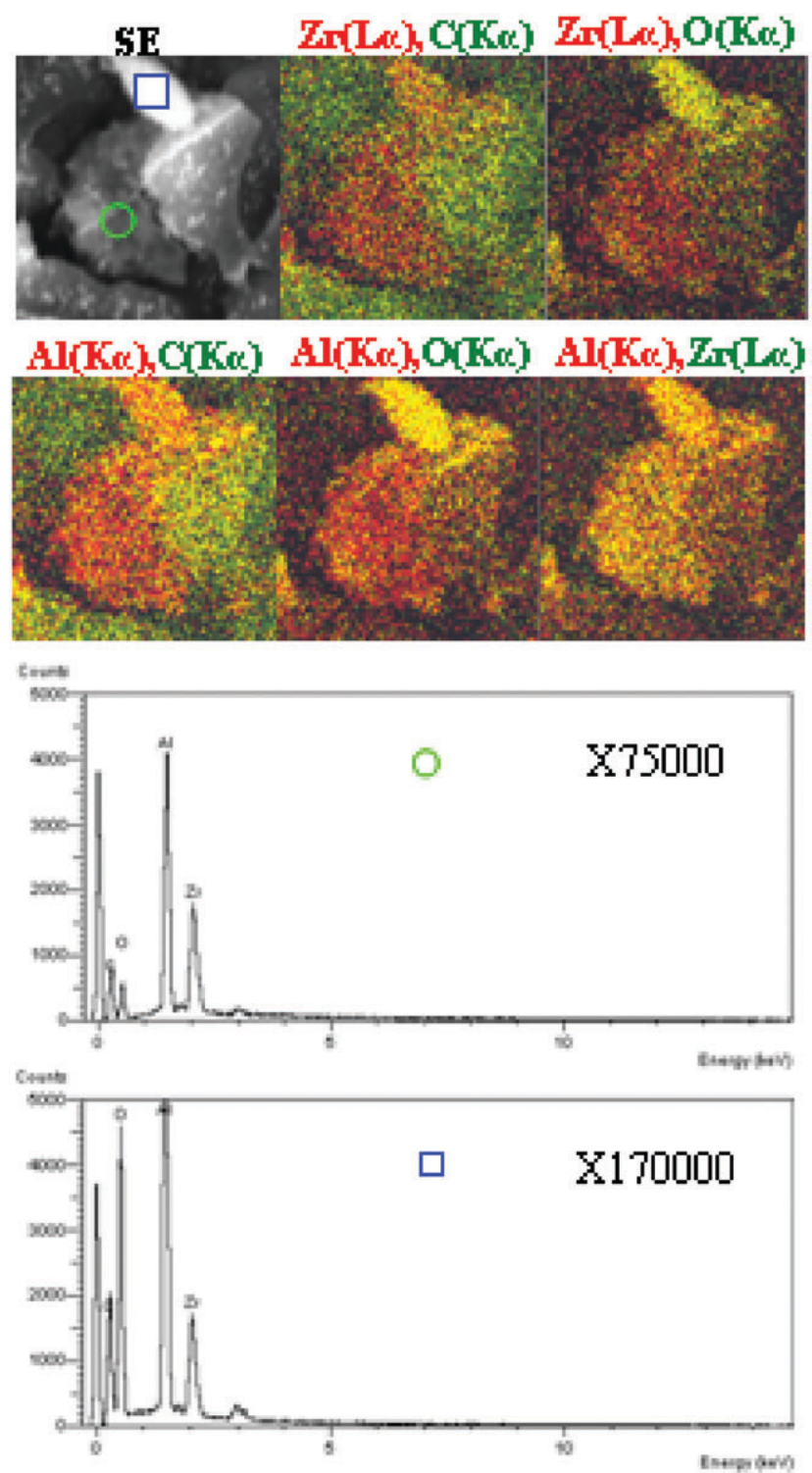

Fig. 5 ED X-ray spectra and coloured superimposed two-element distribution mappings, taken as in Fig. 3, but from a non-pyrolytic graphite platform heated to $1400{ }^{\circ} \mathrm{C}$. plots (Fig. 6A(b)). The irregular particles are constituted by two superimposed layers, which have important differences in their chemical composition and morphology (Fig. 6B). The bottom layer is mainly composed of a mixture of zirconia and alumina, while the top layer is formed by flower-like particles mainly constituted by Zr (Fig. 6B(a)). Differences in the spatial distributions of $\mathrm{Zr}$ and $\mathrm{Al}$ are clearly noted in the flower-like structures (Fig. 6B(b)), which suggests that the thermal chemistry of the elements tends to demonstrate more independent behaviour at temperatures above $1500{ }^{\circ} \mathrm{C}$.

When pyrolytic graphite platforms were used, similar results to those for the non-pyrolytic platforms were obtained: a mixture of zirconia and alumina exists at $1500{ }^{\circ} \mathrm{C}$ (Fig. 7A); there is evidence of some $\mathrm{Zr}-\mathrm{Al}$ alloy formation at $1800{ }^{\circ} \mathrm{C}$ (Fig. 7B and Fig. 7C); zirconium carbide seems to be formed at the edges of some particles (Fig. 7A). The main difference was that reduction of zirconia and alumina occurred at higher temperatures on a pyrolytic graphite platform than on a nonpyrolytic platform (Fig. 2). Also, it was observed that particles with the same chemical and morphological characteristics were formed on the two types of platform, but at higher temperatures with a pyrolytic graphite platform (Fig. 7B).

At $2300{ }^{\circ} \mathrm{C}$, the composition of the particles varies with the location on the pyrolytic platform. Particles towards the edge of the platform, close to the hole where the platform is introduced, contain mainly aluminium, maybe with some aluminium carbide (Fig. 8A). At the centre of the platform surface, particles of $\mathrm{Zr}-\mathrm{Al}$ alloy were formed (Fig. 8B); carbides of aluminium and zirconium seem also to exist at some locations (Fig. 8C). Also, flower-like particles comprising mainly $\mathrm{Zr}$, similar to those found on non-pyrolytic graphite platforms at lower temperatures $\left(1800^{\circ} \mathrm{C}\right)$, exist on a zirconiaalumina layer (Fig. 8D).

Prolonged heating at $2300{ }^{\circ} \mathrm{C}$ or higher temperatures, such as those achieved applying a full heating cycle, caused complete vaporisation of aluminium from the platform; minor amounts of $\mathrm{Zr}$ particles remained, provided at least $100 \mu \mathrm{g}$ had been injected (Fig. 9). It is possible that a thin coating of $\mathrm{Zr}$ could be built up on the platform surface, similar to the permanent modification process, through thermal treatment of successive injections of large amounts of zirconium, but the durability of such a coating is doubtful.

Thermal treatment of the zirconium salt alone, on either type of platform, results initially in the formation of zirconia, which is reduced to $\mathrm{Zr}$ at higher temperatures (Fig. 10). The ratio of 

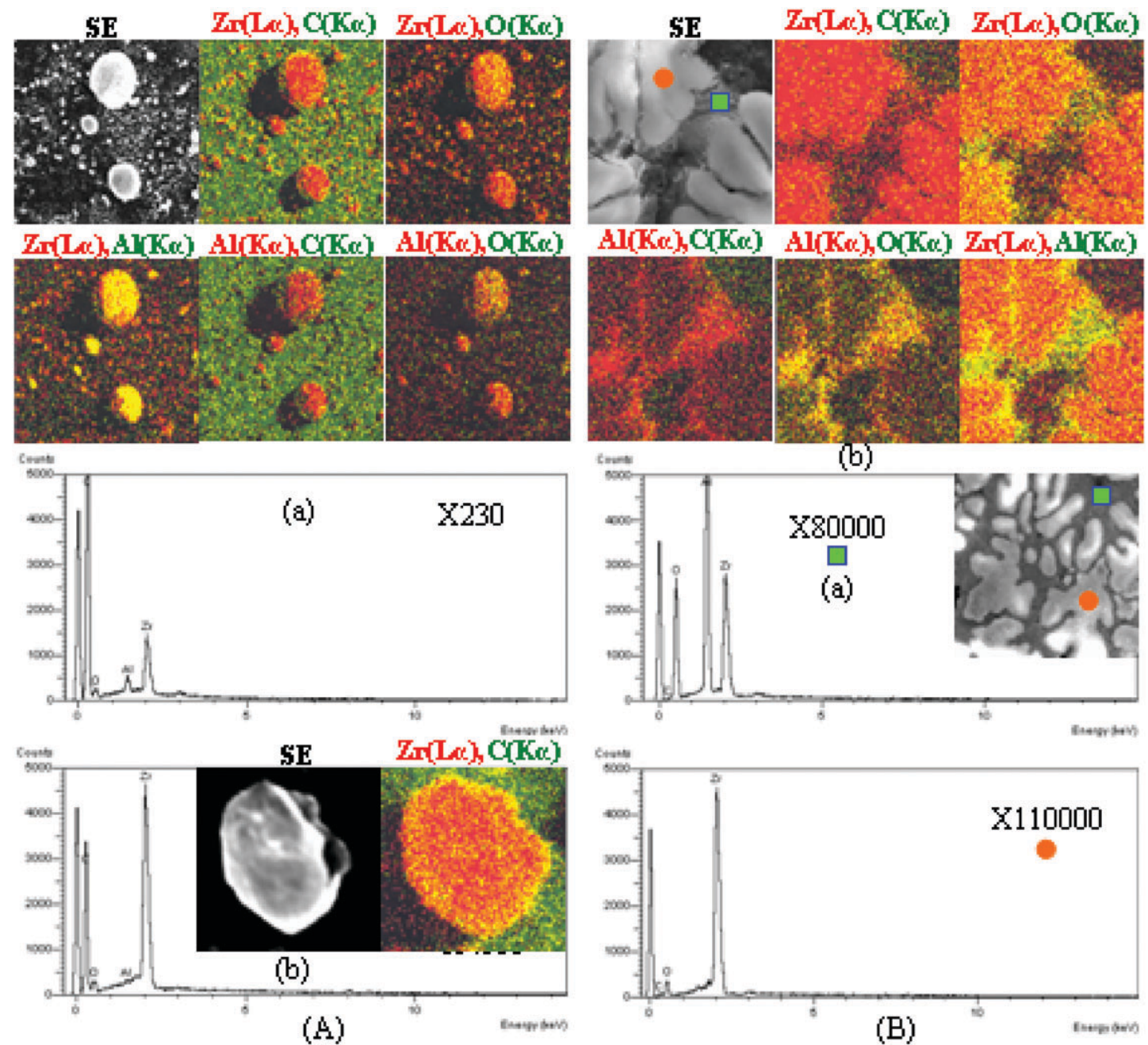

Fig. 6 ED X-ray spectra with the corresponding SEM mappings and coloured superimposed two-element distribution mappings, taken as in Fig. 5, but heated to $1800{ }^{\circ} \mathrm{C}$ and showing (A) round particles and (B) flower-like particles. The SEM picture in B(b) shows the element distribution mappings from a small location derived from $\mathrm{B}(\mathrm{a})$.

$\mathrm{Zr}$ to $\mathrm{O}$ in the particles increases as the temperature increases, and is also greater in smaller particles (Fig. 10A). Small particles have a larger surface area to volume ratio than do larger particles, which favours the reduction of zirconia by carbon. Larger particles of zirconia were observed to have formed $\mathrm{Zr}$ metal, maybe zirconium carbide, in some instances, at the edges (Fig. 10B) where there is contact with the graphite surface.

\section{Raman and infrared spectra}

Raman spectra of the zirconium salt alone on a non-pyrolytic platform, heated to $1000{ }^{\circ} \mathrm{C}$ and $1500{ }^{\circ} \mathrm{C}$, are similar (Fig. 11A). The main peaks are at 175.1, 187.4, 219.0, 302.7, 330.4, $342.5,377.0,472.8,501.7,533.5,555.8,611.3$, and $633.0 \mathrm{~cm}^{-1}$ and are typical of the monoclinic phase of zirconia. ${ }^{31,32} \mathrm{At}$ $1800{ }^{\circ} \mathrm{C}$, some particles also have this spectrum (Fig. 11B), but a different spectrum was obtained at other locations on the platform surface (Fig. 11C), possibly due to formation of zirconium carbide, although this could not be substantiated by reference to the literature.

When mixtures of zirconium and aluminium salts were heated on the platform, the Raman spectra were dependent on the temperature and location on the platform surface. At $1400{ }^{\circ} \mathrm{C}$, the Raman spectra have peaks at 146, 271, 315, 460 and $646 \mathrm{~cm}^{-1}$ (Fig. 11D), which confirms formation of the tetragonal phase of zirconia. ${ }^{31}$ At $1800{ }^{\circ} \mathrm{C}$, different spectra were recorded at various locations (Fig. 11E), including a pattern of peaks (Fig. 11F) indicative of monoclinic zirco- nia. ${ }^{31,32}$ Raman spectra were also identified that originate from Al species. The spectra for a platform heated to $1400{ }^{\circ} \mathrm{C}$ (Fig. 11D) has peaks at 418, 451, 619, 646 and $648 \mathrm{~cm}^{-1}$, which are typical of alumina. ${ }^{33-36}$ The Raman spectrum taken after heating to $1800{ }^{\circ} \mathrm{C}$ has a peak at $617.7 \mathrm{~cm}^{-1}$ (Fig. $11 \mathrm{~F}$ ), caused by the $\mathrm{AlOH}$ deformation $\gamma(\mathrm{OH})$ mode, which suggests the existence of hydroxy $\mathrm{Al}$ species, ${ }^{37,38}$ possibly $\mathrm{AlO}(\mathrm{OH})$. However, there is also strong evidence of the transformation of hydroxyaluminium species into $\mathrm{Al}$ oxide, as the Raman spectra also contain peaks at 345, 418 and around $646-648 \mathrm{~cm}^{-1}$ (Fig. $11 \mathrm{D}$ and $11 \mathrm{E}$ ), which can be assigned to $\mathrm{Al}-\mathrm{O}-\mathrm{Al}$ skeletal flexing vibrations, indicating the presence of dehydrated $\mathrm{Al}_{2} \mathrm{O}_{3} .{ }^{33,34,36}$ The observations relating to the zirconia phases agree with those derived from other studies, ${ }^{37,38}$ where it was stated that the tetragonal phase is localised close to the metal/ oxide interface. The tetragonal phase derived from the monoclinic phase cannot be quenched to room temperature, but doping with an oxide, like alumina, stabilises it at lower temperatures. The Raman spectra show that the presence of alumina prevents the tetragonal to monoclinic transformation by matrix constraint. The influence of alumina on the phase of zirconia is not unique. When $10 \mu \mathrm{g}$ of As was added to $100 \mu \mathrm{g}$ of $\mathrm{Zr}$ and heated to different temperatures, the surface analysis techniques revealed evidence of interactions between the species. Fig. 12A shows that aggregates and finely dispersed particles are produced on heating to $900{ }^{\circ} \mathrm{C}$. Mixed oxides of As and $\mathrm{Zr}$ were evident up to $1400{ }^{\circ} \mathrm{C}$. Raman spectra (Fig. 12B) show that the tetragonal phase of zirconia is dominant in the presence of $10 \mu \mathrm{g}$ of As, but that mixtures of the monoclinic 

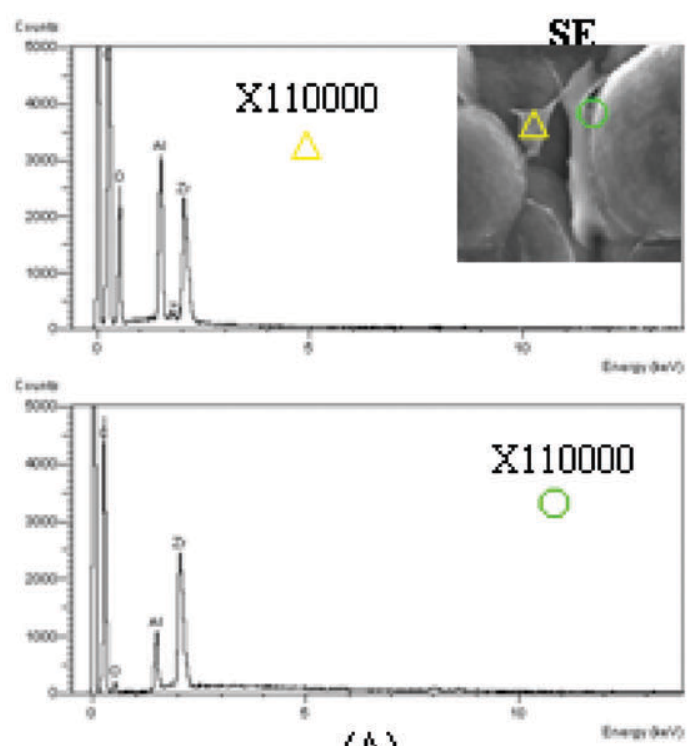

(A)
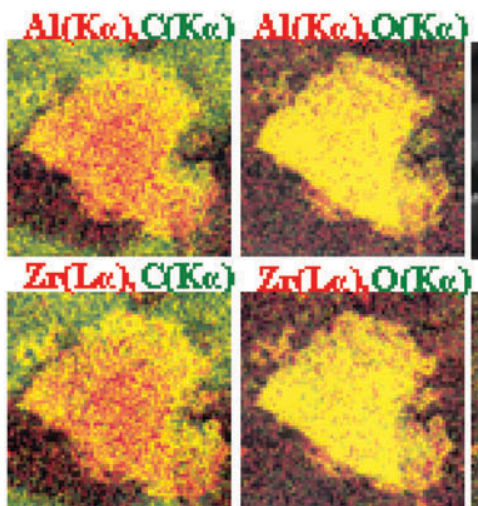

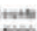

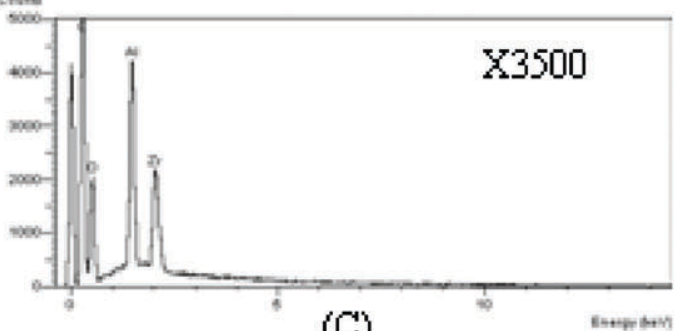

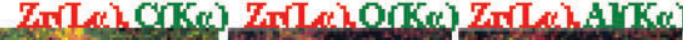
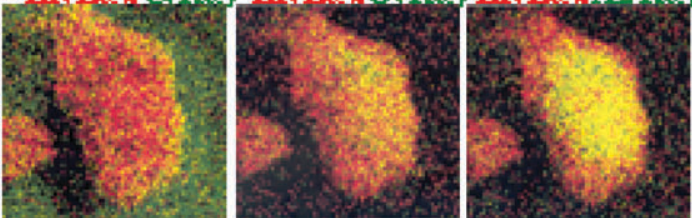

AlKu CrKa
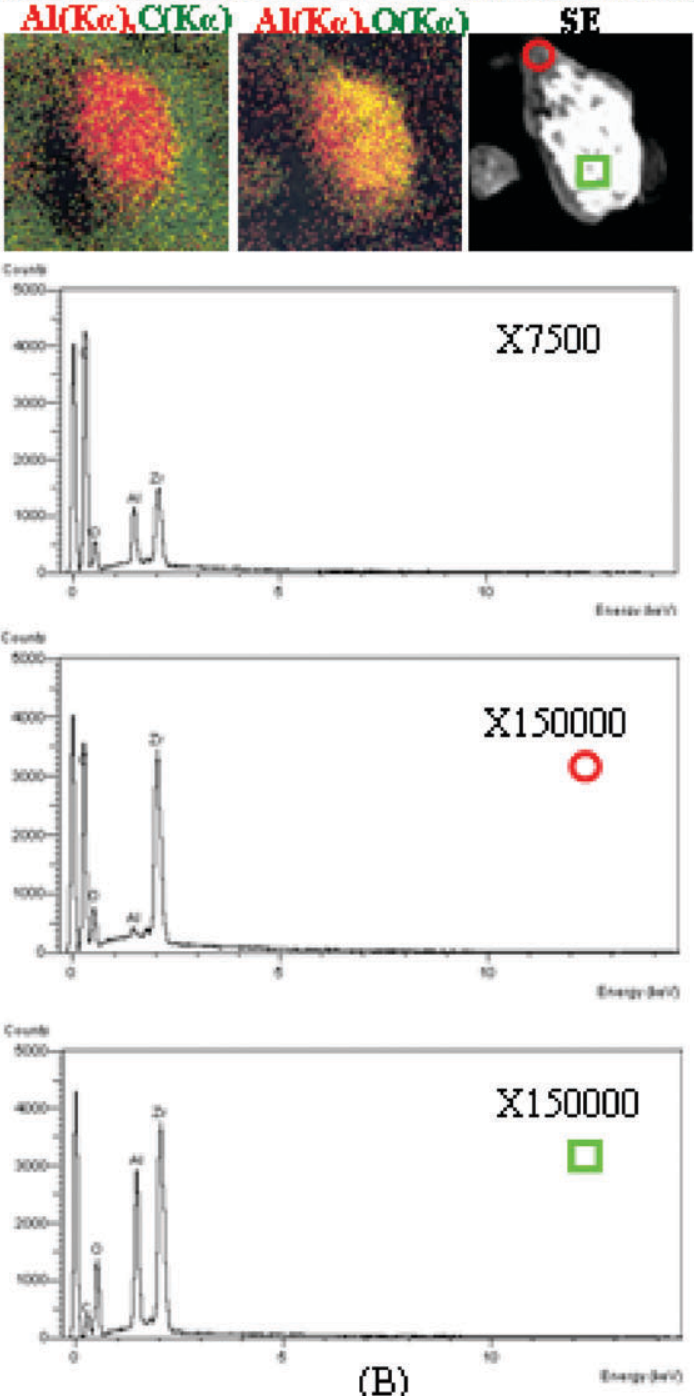

(B)

Fig. 7 ED X-ray spectra and coloured superimposed two-element distribution mappings from a pyrolytic graphite platform containing $100 \mu$ g each of aluminium and ziconium salts heated to (A) $1500{ }^{\circ} \mathrm{C}$ and $(\mathrm{B}, \mathrm{C}) 1800{ }^{\circ} \mathrm{C}$. (B) and (C) represent two different areas on the same platform.

and tetragonal phases of zirconia exist if only $0.5 \mu \mathrm{g}$ of As is added to $\mathrm{Zr}$. If $\mathrm{Zr}$ were to be used as a modifier for determination of ng or pg amounts of As, it is unlikely that the analyte would have any effect on the phase change of zirconia; it will only be the larger amounts of concomitant matrix salts (such as $\mathrm{Al})$ that will prevent phase changes.

Truncated FT-IR spectra of the salt residues from zirconium alone and zirconium mixed with aluminium are shown in Fig. 13 for different temperatures. For the case of zirconium alone, the absorption band at $402-410 \mathrm{~cm}^{-1}$ (Fig. 13A) is indicative of the presence of monoclinic $\mathrm{ZrO}_{2}{ }^{39-41}$ in agreement with the results derived by Raman spectrometry. The band decreased in magnitude as the temperature was increased, indicating a decrease in the amount of monoclinic zirconia on the platform surface. A small absorption band at $430 \mathrm{~cm}^{-1}$ also suggests the presence of very small amounts of tetragonal $\mathrm{ZrO}_{2}$ up to $1400{ }^{\circ} \mathrm{C} .{ }^{41}$ These absorption bands and other less intense features at about 419 and $445 \mathrm{~cm}^{-1}$ (Fig. 13A) are characteristics of $\mathrm{Zr}-\mathrm{O}$ stretching and bending vibrations of $\mathrm{ZrO}_{2}$ in $\mathrm{ZrO}_{\delta}$ polyhedra, where usually $\delta=4$ or $6 .^{40,42}$ The absence of a broad band at $800-810 \mathrm{~cm}^{-1}$ is indicative of the good degree of crystallinity of the dry residue. For the mixture of zirconium and aluminium, no significant absorption bands appeared in the spectral ranges of $700-1300$ and $3000-3800 \mathrm{~cm}^{-1}$, meaning that the $\mathrm{Al}-\mathrm{OH}$ bend and $\mathrm{AlO}-\mathrm{H}$ stretch are absent or present in minor extension here. The strong band at $442 \mathrm{~cm}^{-1}$ (Fig. $13 \mathrm{~B})$ is due to $\mathrm{Al}-\mathrm{O}$ stretching vibrations ${ }^{43,44}$ and its relative intensity seems to increase with temperature. Nonetheless, it can also be affected by contributions from the $\mathrm{Zr}-\mathrm{O}$ stretching and bending vibrations. Other intense bands were observed at $469 \mathrm{~cm}^{-1}$ at $1000{ }^{\circ} \mathrm{C}$, and 458,469 and $475 \mathrm{~cm}^{-1}$ at $1400{ }^{\circ} \mathrm{C}$, while less intense peaks at 455 and $466 \mathrm{~cm}^{-1}$ were also noted at $1800{ }^{\circ} \mathrm{C}$ (Fig. 13B). All these peaks have been attributed to $\mathrm{Al}-$ $\mathrm{O}-\mathrm{Al}$ bend $\left(\mathrm{AlO}_{6}\right)$ and $\mathrm{Zr}-\mathrm{Al}$ vibrations. ${ }^{45}$ When FT-IR spectra from zirconium and zirconium mixed with aluminium are compared, the presence of monoclinic zirconia is more evident for $\mathrm{Zr}$ alone, confirming the stabilisation of the tetragonal phase of zirconia in the presence of alumina.

Many of the results reported in this work are thermodynamically supported. For example, the formation of zirconium 

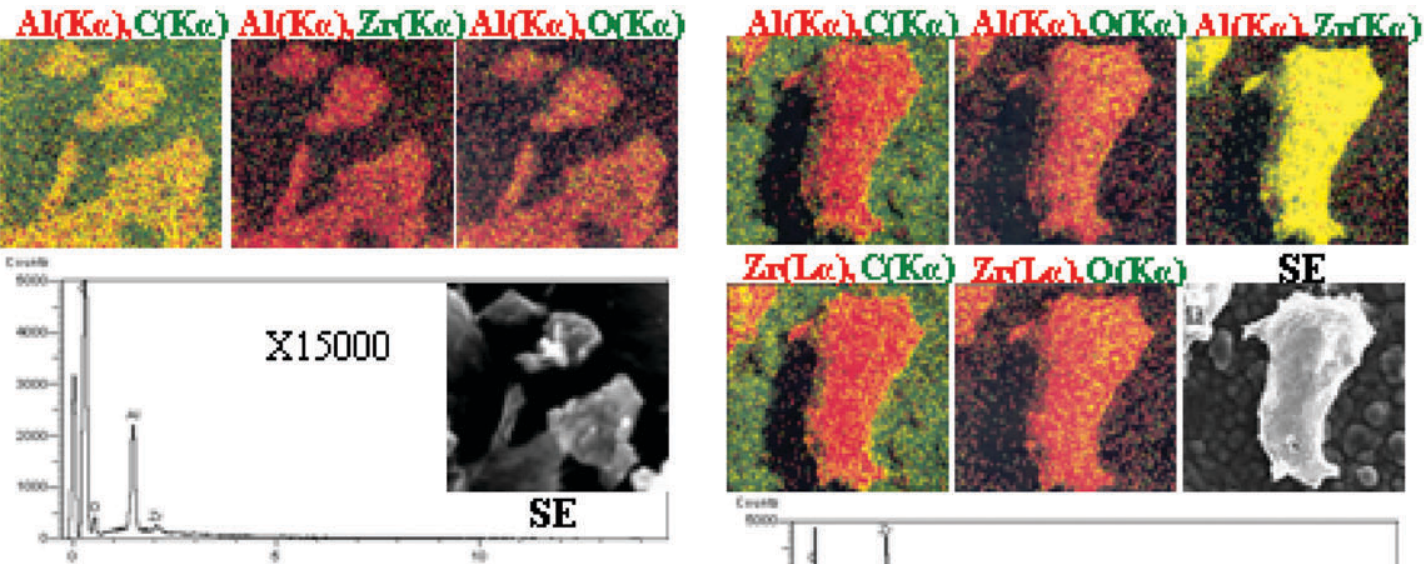

(A)
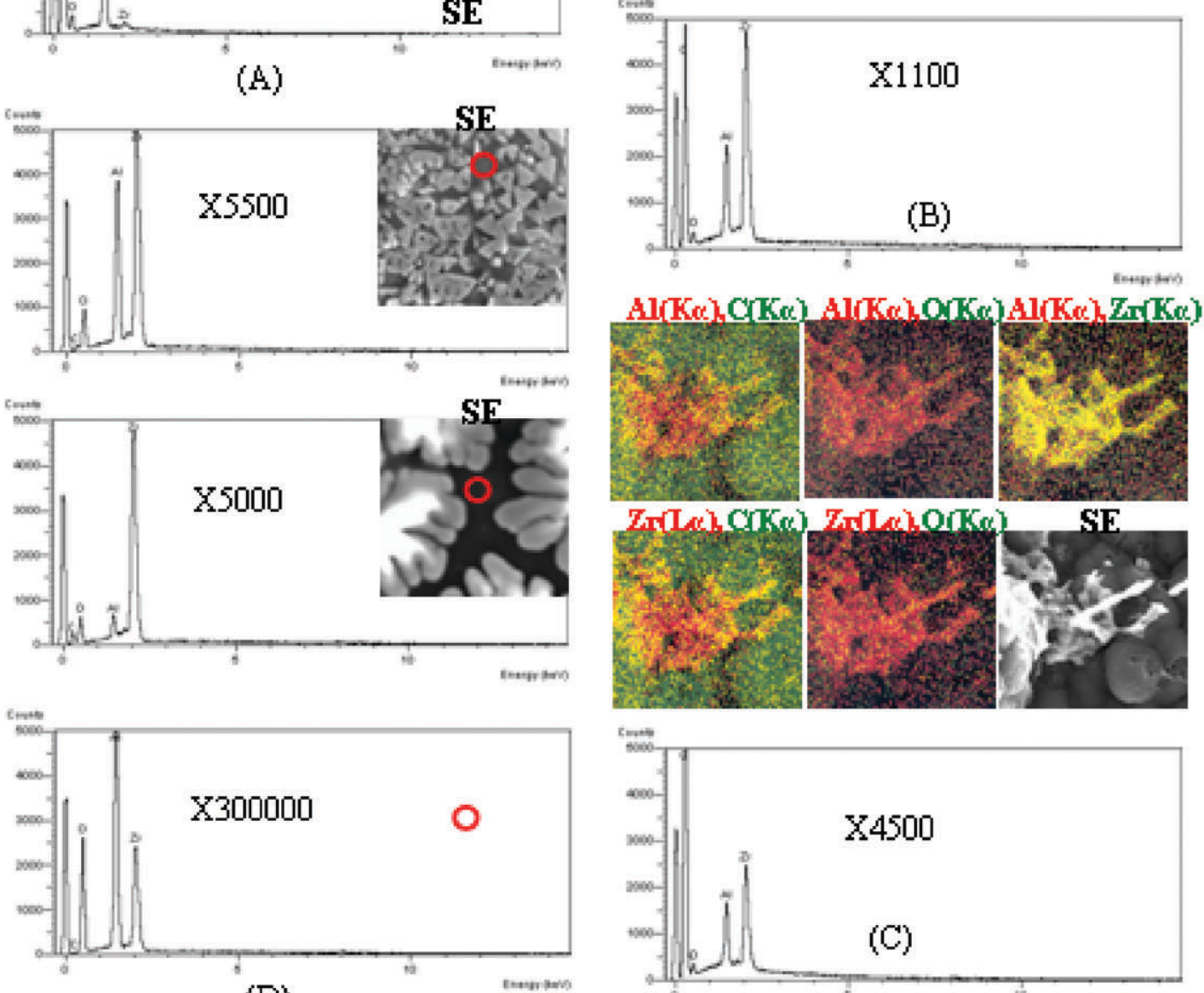

(D)

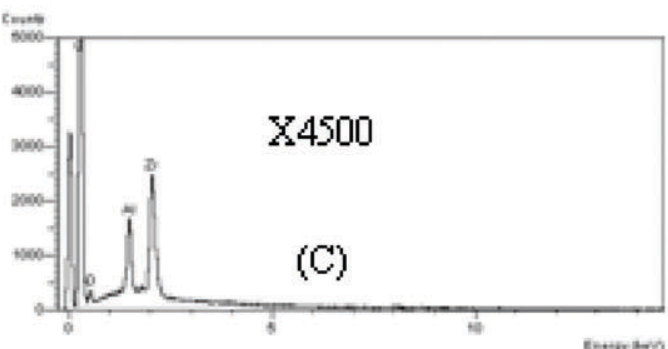

Fig. 8 ED X-ray spectra and element distribution mappings from (A) outer and (B, C, D) inner regions of a pyrolytic graphite platform containing $100 \mu \mathrm{g}$ each of aluminium and ziconium salts heated to $2300^{\circ} \mathrm{C}$. The pictures and ED X-ray spectra included in (B, C, D) were taken from different locations on the inner region of the same platform.

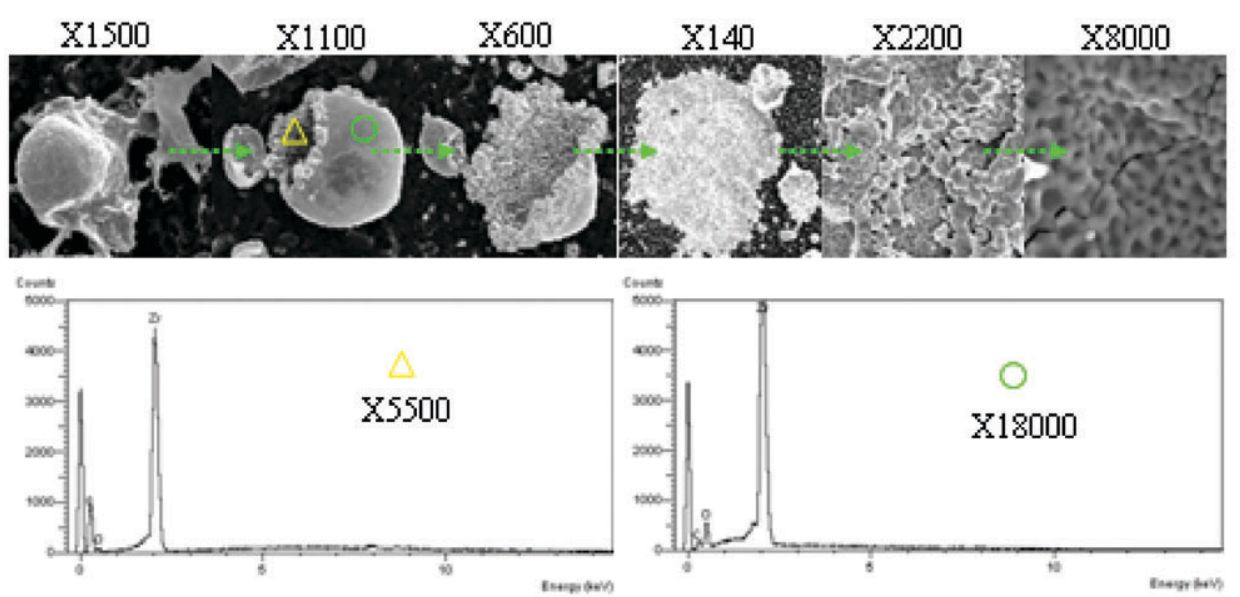

Fig. 9 ED X-ray spectra and SEM mappings from a pyrolytic graphite platform containing $100 \mu \mathrm{g}$ each of aluminium and zirconium salts heated to $2300{ }^{\circ} \mathrm{C}$ for $4 \mathrm{~s}$. The arrows show how the solid residue metamorphosed to form a zirconium coating at high temperatures. Similar results were derived after a full heating cycle. 

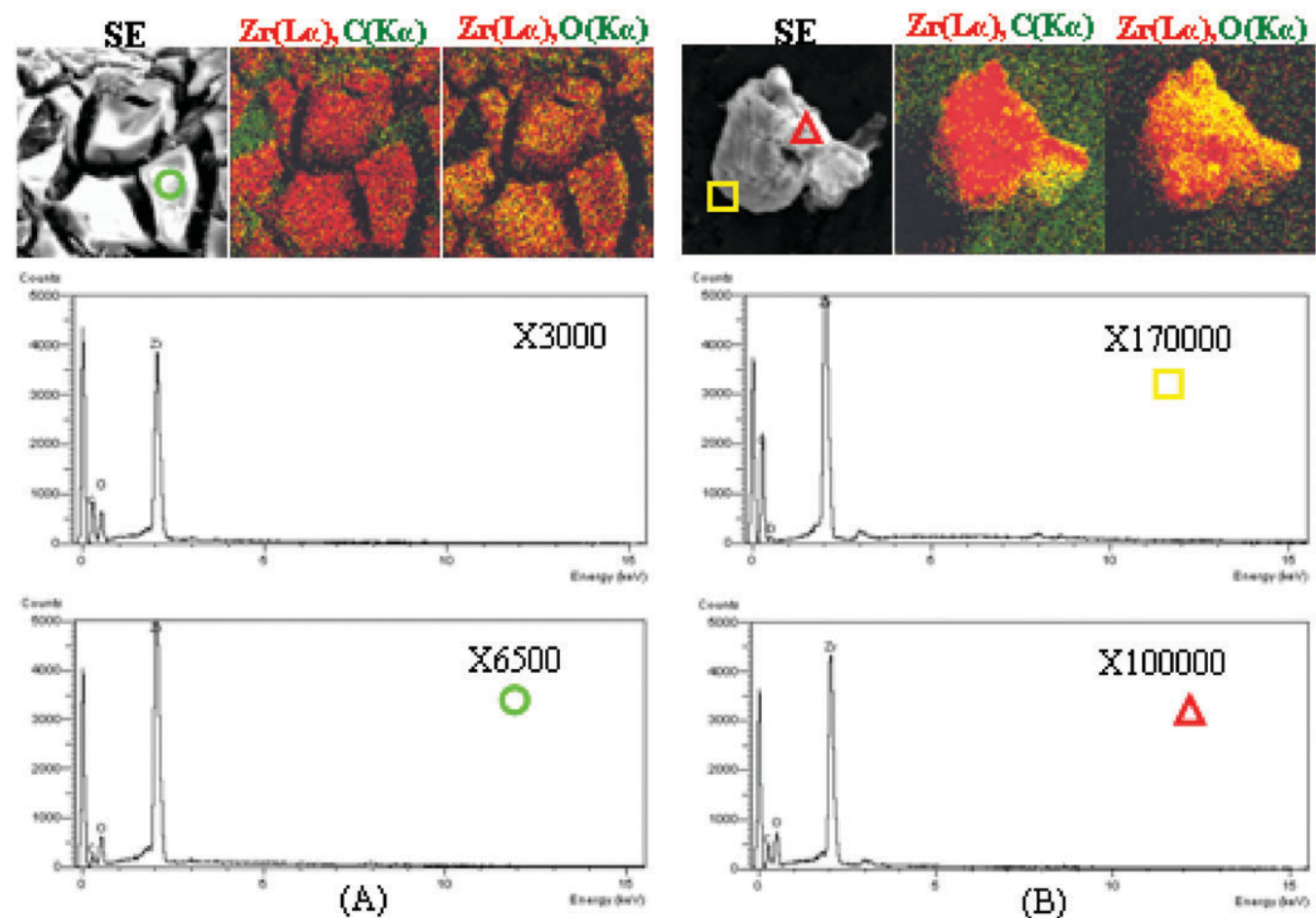

Fig. 10 ED X-ray spectra and element distribution mappings from a non-pyrolytic graphite platform containing $100 \mu \mathrm{g}$ of zirconium salt heated to (A) $1400{ }^{\circ} \mathrm{C}$ and (B) $1600^{\circ} \mathrm{C}$.
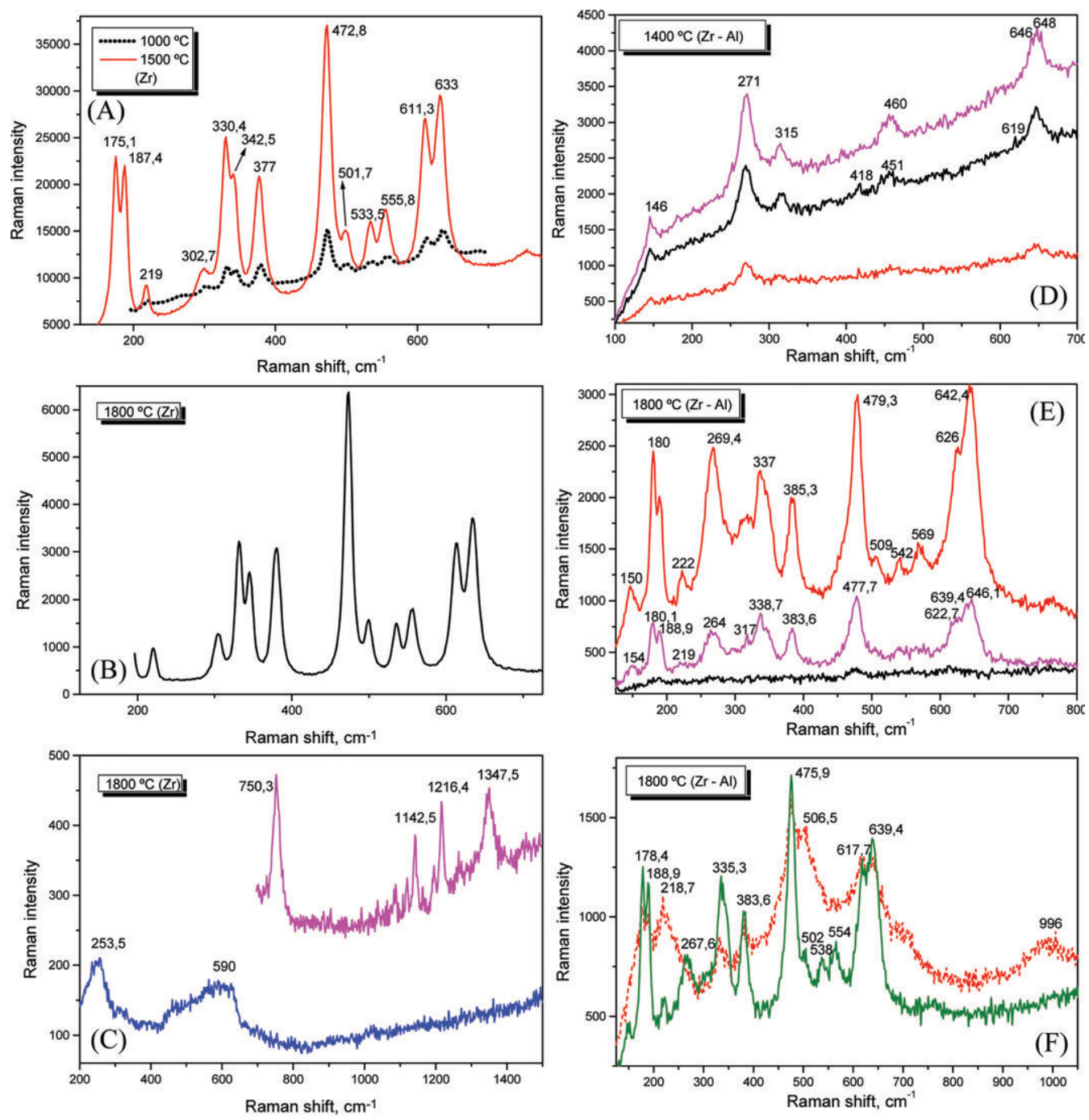

Fig. 11 Raman spectra from a non-pyrolytic graphite platform containing (A, B, C) $100 \mu \mathrm{g}$ of zirconium salt and (D, E, F) $100 \mu \mathrm{g}$ each of aluminium and ziconium salts heated to different temperatures. Raman spectra shown at the same temperature derived from different locations on the graphite platform surface. 


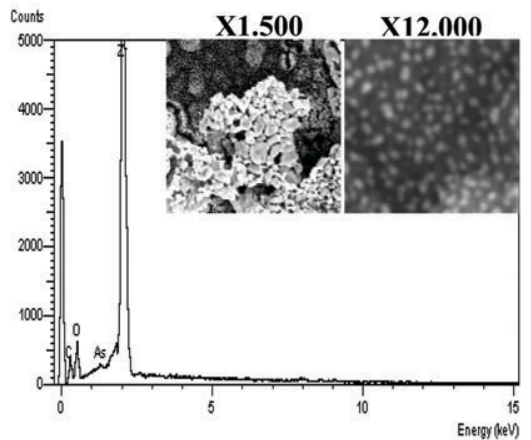

(A)

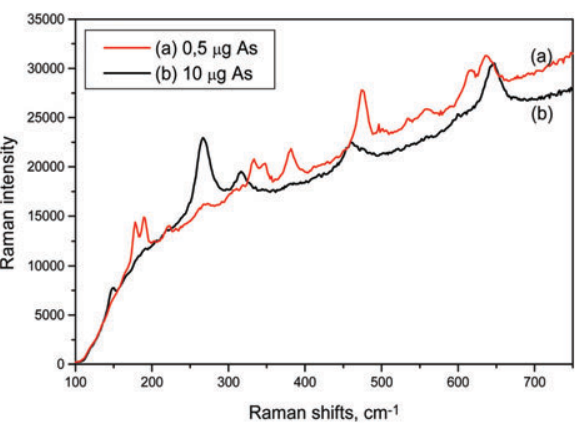

(B)

Fig. 12 (A) ED X-ray spectrum and SEM mappings from a pyrolytic graphite platform containing $10 \mu \mathrm{g}$ of arsenic and $100 \mu \mathrm{g}$ of ziconium salts heated to $900^{\circ} \mathrm{C}$. (B) Raman spectra from the same pyrolytic graphite platform containing two amounts of arsenic. Raman spectrum (a) shows a mixture of tetragonal and monoclinic phases, while Raman spectrum (b) shows a typical tetragonal phase.

(A)

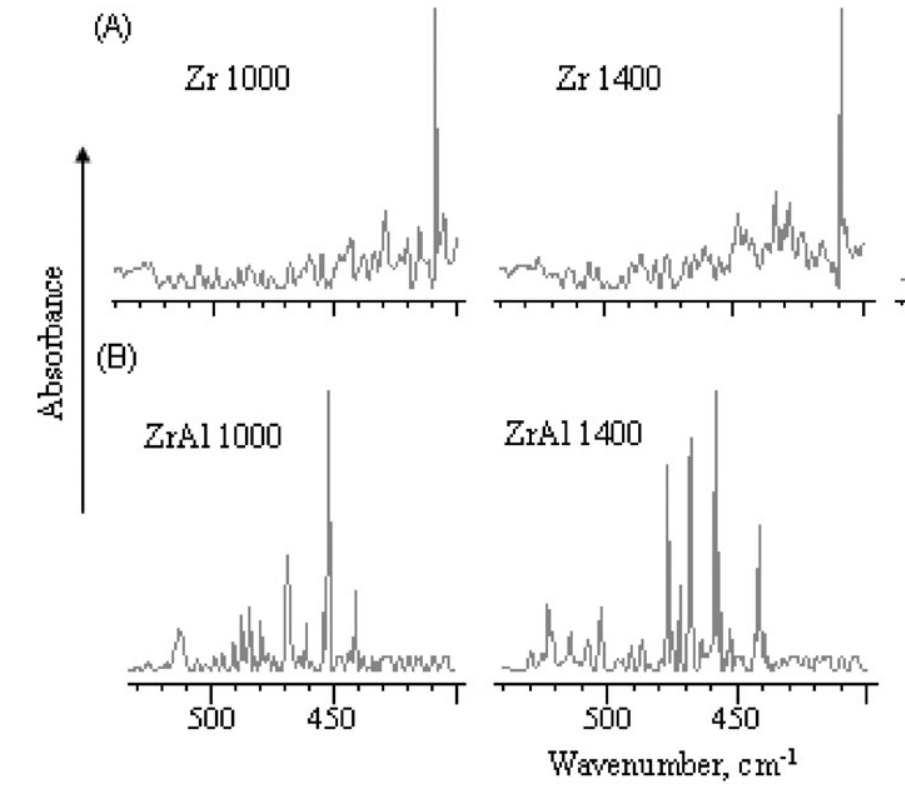

$\mathrm{Zr} 1800$
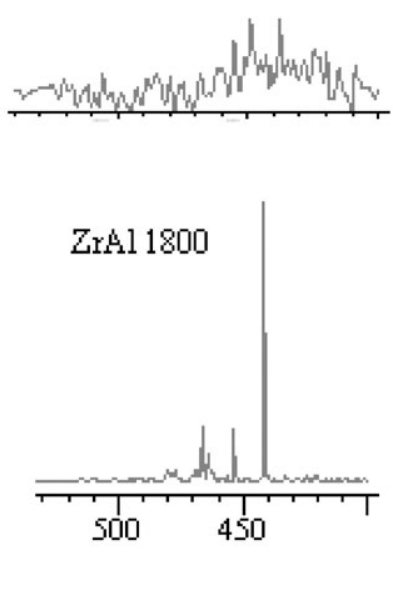

Fig. 13 FT-IR spectra from a pyrolytic graphite platform containing (A) $100 \mu \mathrm{g}$ of zirconium salt and (B) $100 \mu \mathrm{g}$ each of aluminium and ziconium salts heated to three temperature values $\left(1000,1400\right.$ and $\left.1800^{\circ} \mathrm{C}\right)$.

metal is thermodynamically more favourable than the formation of zirconium carbide for increasing temperature. ${ }^{46,47}$ However, the slow kinetics of the chemical transformations involved and minimal contact between the reactants $(\mathrm{C}$ and $\mathrm{Zr}$ species) are likely to be behind some of the discrepancies established, including the existence of zirconia at comparatively high temperatures. Furthermore, aluminium also tends to form aluminium metal vapour or aluminium oxide in the gas phase, ${ }^{23}$ which would be removed from the tube. Overall, the findings of this work agree in the main with those derived by De Giglio et al. ${ }^{48}$ who also stated that oxygen-containing species are predominant in the thermo-chemical transformations of $\mathrm{Zr}$, while the absence of zirconium carbide seems to be evident.

\section{Conclusions}

The main conclusion is that the thermochemical behaviour of zirconium salt residues on the platform surface is not strongly dependent upon the substrate type; the only difference observed was that chemical and physical transformations occurred at higher temperatures on pyrolytic graphite platforms than on non-pyrolytic ones. However, the presence of aluminium has an influence on the morphology and transformations of zirconium species; the two elements were found to be associated with oxygen, even at relatively high temperatures $\left(1400{ }^{\circ} \mathrm{C}\right)$, with some solid solutions formed. At higher temperatures, $\mathrm{Zr}-\mathrm{Al}$ alloy was found at some locations on the platform surface, but in general, the elements followed independent thermochemical pathways, with $\mathrm{Zr}$ metal the prevalent species at $2500{ }^{\circ} \mathrm{C}$. Zirconium or aluminium carbides were not conclusively detected.

The results of this work also have important analytical implications. The action of zirconium as a permanent modifier in ETAAS has been thought to involve the formation of zirconium carbide. However, this does not seem to be the case, as zirconium oxide and zirconium metal are the predominant species formed at temperatures below and above $1500{ }^{\circ} \mathrm{C}$, respectively. This suggests that, at low and intermediate temperatures, zirconium-based modifiers are effective as a modifier by stabilising volatile analytes that become trapped in a lattice (network) of zirconia, or other oxides that show some isomorphism with zirconia. At temperatures higher than $1500{ }^{\circ} \mathrm{C}$, zirconium metal becomes the prevalent species, and the retained analyte will be progressively released from the zirconia lattice; further stabilisation will only occur if the analyte can form some compound with $\mathrm{Zr}$. In the case of interference by aluminium, the presence of zirconium may retard the generation of gaseous interfering species through interaction between alumina and zirconia (solid solution) at low temperatures $\left(<1500{ }^{\circ} \mathrm{C}\right)$. 


\section{References}

1 R. D. Ediger, At. Absorption Newsl., 1975, 14, 127-130.

2 X.-Q. Shan, Z.-M. Ni and L. Zhang, Anal. Chim. Acta, 1983, 151, $179-185$.

3 Z.-M. Ni and X.-Q. Shan, Spectrochim. Acta, Part B, 1987, 42, 937-949.

4 G. Schlemmer and B. Welz, Spectrochim. Acta, Part B, 1986, 41, $1157-1165$

5 A. B. Volynsky and R. Wennrich, Spectrochim. Acta, Part B, 2002, 57, 1301-1316.

6 F. Laborda, J. Medrano, J. I. Cortés, J. M. Mir and J. R. Castillo, Spectrochim. Acta, Part B, 1999, 54, 343-353.

7 M. A. Castro, C. García-Olalla, L. C. Robles and A. J. Aller, Spectrochim. Acta, Part B, 2002, 57, 1-14.

8 R. Nowka, K. Eichardt and B. Welz, Spectrochim. Acta, Part B, 2000, 55, 517-524.

9 A. V. Flores, C. A. Pérez and M. A. Z. Arruda, Talanta, 2004, 62, 619-626.

10 T. Saint'Pierre, R. Q. Aucélio and A. J. Curtius, Microchem. J., 2003, 75, 59-67.

11 D. L. Tsalev, L. Lampugnani, R. Georgieva, K. K. Chakarova and I. I. Petrov Jr, Talanta, 2002, 58, 331-340.

12 Y. P. Liao and H. O. Haug, Microchem. J., 1997, 56, 247-258.

13 V. I. Slaveykova, L. Lampugnani, D. L. Tsalev and L. Sabbatini, Spectrochim. Acta, Part B, 1997, 52, 2115-2126.

14 V. I. Slaveykova, L. Lampugnani, D. L. Tsalev, L. Sabbatini and E. De Giglio, Spectrochim. Acta, Part B, 1999, 54, 455-467.

15 D. L. Tsalev, V. I. Slaveykova, L. Lampugnani, A. D'Ulivo and R. Georgieva, Spectrochim. Acta, Part B, 2000, 55 473-490.

16 A. B. Volynsky, Spectrochim. Acta, Part B, 1998, 53, 509-535.

17 A. B. Volynsky, Spectrochim. Acta, Part B, 1998, 53, 1607-1645.

18 H. M. Ortner, E. Bulska, U. Rohr, G. Schlemmer, S. Weinbruch and B. Welz, Spectrochim. Acta, Part B, 2002, 57, 1835-1853.

19 B. V. L'vov, J. Anal. At. Spectrom., 1987, 2, 95-104.

20 B. V. L'vov, L. K. Polzik, N. P. Romanova and A. I. Yuzefovskii, J. Anal. At. Spectrom., 1990, 5, 163-169.

21 J. A. Holcombe, D. L. Styris and J. D. Harris, Spectrochim. Acta Part B, 1991, 46, 629-639.

22 M. M. Lamoureux, C. L. Chakrabarti, J. C. Hutton, A. Kh Gilmutdinov, Y. A. Zakharov and D. C. Grégoire, Spectrochim. Acta, Part B, 1995, 50, 1847-1867.

23 M. A. Castro and A. J. Aller, Spectrochim. Acta, Part B, 2003, 58 903-920.

24 U. Rohr, H. M. Ortner, G. Schlemmer, S. Weinbruch and B. Welz, Spectrochim. Acta, Part B, 1999, 54, 699-718.
25 E. Bulska, B. Thybusch and H. M. Ortner, Spectrochim. Acta, Part B, 2001, 56, 363-373.

26 H. M. Ortner, U. Rohr, G. Schlemmer, S. Weinbruch and B. Welz, Spectrochim. Acta, Part B, 2002, 57, 243-260.

27 M. A. Castro, J. C. Feo and A. J. Aller, J. Anal. At. Spectrom. 2003, 18, 260-267.

28 M. A. Castro, K. Faulds, W. E. Smith, A. J. Aller and D. Littlejohn, Spectrochim. Acta, Part B, 2004, 59, 827-839.

29 M. A. Castro, K. Faulds, W. E. Smith, A. J. Aller and D. Littlejohn, Spectrochim. Acta, Part B, 2004, 59, 1935-1942.

30 S. Damyanova, P. Grange and B. Delmon, J. Catal., 1997, 168, 421-430.

31 P. Barberis, T. Merle-Méjean and P. Quintard, J. Nucl. Mater., 1997, 246, 232-243.

32 X. Gao, J. M. Jehng and I. E. Wachs, J. Catal., 2002, 209, 43-50.

33 A. Aminzadeh and H. Sarikhani-Fard, Spectrochim. Acta, Part A, 1999, 55, 1421-1425.

34 R. Krishan, R. Kesavamoorthy, S. Dash, A. K. Tyagi and B. Raj, Scripta Materialia, 2003, 48, 1099-1104.

35 H. R. Ruan, R. L. Frost and J. T. Kloprogge, J. Raman Spectrosc., 2001, 32, 745-750.

36 A. Misra, H. D. Bist, M. S. Navati, R. K. Thareja and J. Narayan, Mater. Sci. Eng. B, 2001, 79, 49-54.

37 P. Bouvier, J. Godlewski and G. Lucazeau, J. Nucl. Mater., 2002, 300, 118-126.

38 L. Duc Huy, P. Laffez, Ph. Danaiel, A. Jouanneaux, N. The Khoi and D. Simeone, Mater. Sci. Eng. B, 2003, 104, 163-168.

39 D. A. Neumayer and E. Cartier, J. Appl. Phys., 2001, 90, 18011808.

40 A. Feinberg and C. H. Perry, J. Phys. Chem. Solids, 1981, 42, 513-518.

41 E. Bonera, G. Scarel and M. Fanciulli, J. Non-Cryst. Solids, 2003, 322, 105-110.

42 A. Mondal and S. Ram, Ceram. Int., 2004, 30, 239-249.

43 R. Brill, F. Koch, J. Mazurelle, D. Levchuk, M. Balden, Y. Yamada-Takamura, H. Maier and H. Bolt, Surf. Coatings Technol., 2003, 174/175, 606-610.

44 D. Santhiya, S. Subramanian, K. A. Natarajan and S. G. Malghan, Colloids Surf. A: Physicochem. Eng. Aspects, 2000, 164, 143-154.

45 D. Voll, P. Angerer, A. Beran and H. Schneider, Vib. Spectrosc., 2002, 30, 237-243

46 National Institute of Standards and Technology, http://www. nist.gov/; http://webbook.nist.gov/chemistry/name-ser.html.

47 Handbook of Chemistry and Physics, CRC Press, Boca Raton, FL, 59th edn., 1978.

48 E. De Giglio, L. Sabbatini, L. Lampugnani, V. I. Slaveykova and D. L. Tsalev, Surf. Interface Anal., 2000, 29, 747-753. 